\title{
Challenge of ensuring access to high-quality emergency surgical care for all
}

\author{
John W Scott, Justin B Dimick
}

Department of Surgery, University of Michigan, Ann Arbor, Michigan, USA

\section{Correspondence to} Dr Justin B Dimick, University of Michigan, Ann Arbor, Ml 48109, USA; jdimick@med.umich.edu

Accepted 18 October 2019 Published Online First 29 October 2019

\section{Sinked}

- http://dx.doi.org/10.1136/ bmjqs-2019-009537

\section{Check for updates}

(c) Author(s) (or their employer(s)) 2020. No commercial re-use. See rights and permissions. Published by BMJ.

To cite: Scott JW, Dimick JB. BMJ Qual Saf

2020;29:613-614.
Emergency general surgery (EGS) encompasses a variety of common acute surgical conditions with high morbidity and mortality that often require timely delivery of resource-intensive care. In the UK, over 30000 patients require an emergency laparotomy each year ${ }^{1}$ and a 2012 audit by the UK Emergency Laparotomy Network revealed a greater than 10 -fold variation in mortality rates between hospitals. ${ }^{2}$ The wide variability in both processes of care and clinical outcomes make EGS a prime target for quality improvement (QI) programmes, whereby promotion of evidence-based practices associated with better outcomes have the potential to impact thousands of lives.

The Enhanced Peri-Operative Care for High-risk patients (EPOCH) trial was designed to evaluate the impact of a national QI programme on survival after emergency abdominal surgery across 93 National Health Service (NHS) hospitals in the UK. ${ }^{1}$ In this trial, a care pathway consisting of 37 consensus-derived best practices was implemented at each hospital using a step-wedged trial design. Over the 85-week study period, the trial failed to demonstrate any significant improvements in mortality, length of stay or readmissions among adults undergoing open emergency abdominal procedures. ${ }^{3}$ When QI efforts aimed at sweeping practice change fail to improve outcomes, they may fail for one of two reasons. First, it may be a failure of implementing the required changes to existing practice. A trial care pathway that is highly complex or resource-intensive may be difficult to fully implement and thus partial implementation may not be sufficient to yield the expected change in outcomes. Second, it is possible that the processes of care targeted by the trial are not independently associated with the outcomes of interest. It may be that they were selected as targets because of previous associations drawn from observational data, but these associations may not prove to be causal under trial conditions.

In this issue of BMJ Quality and Safety, Stephens and colleagues provide insight into the first problem of ineffective implementation. ${ }^{4}$ The authors used a hospitallevel time-series analysis and run charts to determine whether or not participation in the EPOCH trial led to actual changes in the 10 processes of care targeted by trial. ${ }^{4}$ They also characterised the relationship between care-pathway implementation and the use of six suggested implementation strategies. Ultimately, they found that only a small number of hospitals improved even half of the 10 targeted processes, but the greatest number of process improvements occurred at the hospitals that used five or more of the suggested implementation strategies. Even this link between using a greater number of implementation strategies and experiencing the greatest number of process improvements is not clearly causal. It is possible that the hospitals that have the most resources and the best ability to change processes of care are also the hospitals that are most able to use more implementation strategies. Overall, these findings suggest that the null findings of the EPOCH trial may have been partially due to incomplete implementation of the care bundle.

Unfortunately, because so few hospitals changed even half of the processes of care, the Stephens study does not provide insight into whether or not the processes of care being studied are actually associated with the clinical outcomes of interest. After the first EPOCH report, a subsequent study from the UK-based Emergency Laparotomy Collaborative (ELC) demonstrated a reduction in 
mortality after implementation of an emergency laparotomy care bundle which focused on just six process measures at only 28 NHS hospitals. ${ }^{5}$ This collaborative provided change management and leadership coaching as well as quarterly feedback in the form of run charts as suggested by Stephens and colleagues. ${ }^{4}$ The ELC trial demonstrated that iterative improvements in care bundle implementation were temporally associated with iterative improvements in mortality and hospital length of stay, thereby suggesting that the processes of care under investigation could be associated with better outcomes. Unfortunately, this study does not prove causation as the lack of a concurrent control group makes it impossible to account for secular trends-a limitation common to many preimplementation/postimplementation studies.

Taken together, the findings of Stephens and colleagues ${ }^{4}$ and the ELC trial ${ }^{5}$ provide valuable insight into the null findings of the initial EPOCH trial. ${ }^{3}$ The Stephens study reveals that most hospitals in the $\mathrm{EPOCH}$ trial did not have robust improvements in most of the processes of care, and their analyses suggest that this lack of process improvement may be driven by insufficient implementation strategies. The ELC trial suggests that effective implementation of the care pathway may actually be associated with improved outcomes. Together, this suggests that the null findings of the original EPOCH trial are driven, at least in part, by incomplete implementation. Unfortunately, the available data stop short of proving a direct and causal line from use of more implementation strategies to improved processes of care to improved outcomes. However, it is apparent that improving EGS outcomes at the national level is difficult and requires collaboration across institutions, continual feedback and significant allocation of time and resources.

Reducing facility-level barriers to implementation is therefore critical to the success of durable QI programmes. Stephens and colleagues highlight the role of using multiple different implementation strategies to drive meaningful process change. However, not every hospital has the same capacity to devote the significant time and resources to QI programme implementation. An important question therefore remains: how will the problem of variable implementation capacity impact existing disparities in access to highquality emergency surgical care? Although all patients are at risk for conditions requiring timely and resourceintensive EGS care, not all patients have access to the best outcomes. Smaller, rural and critical-access rural hospitals have fewer material and human resources ${ }^{6}$ and may have more difficulty with burdensome and resource-intensive implementation efforts. These critical access hospitals provide disproportionally care for marginalised patient populations and thus QI implementation failure may only widen pre-existing disparities in access to high-quality care. ${ }^{7}$ It is therefore imperative that QI programmes of any size tailor their implementation strategies to the local context. And in this case, that context includes variability in available hospital resources. In fact, particular emphasis will need to be placed on supporting the lower-resourced hospitals with the greatest barriers to implementation. The unique challenges they face may require unique solutions to achieve the same degree of improvement as their better-resourced counterparts. The end goal, after all, is not to produce more equal hospital inputs, but rather more equitable patient outcomes.

Funding The authors have not declared a specific grant for this research from any funding agency in the public, commercial or not-for-profit sectors.

Competing interests None declared.

Patient consent for publication Not required.

Provenance and peer review Commissioned; internally peer reviewed.

\section{REFERENCES}

1 NELA project team. First patient report of the National emergency laparotomy audit. London: Royal College of Anaesthetists, 2015. https://www.nela.org.uk/All-PatientReports\#pt

2 Saunders DI, Murray D, Pichel AC, et al. Variations in mortality after emergency laparotomy: the first report of the UK emergency laparotomy network. Br J Anaesth 2012;109:368-75.

3 Peden CJ, Stephens T, Martin G, et al. Effectiveness of a national quality improvement programme to improve survival after emergency abdominal surgery (epoch): a stepped-wedge cluster-randomised trial. The Lancet 2019;393:2213-21.

4 Stephens TJ, Peden CJ, Haines R, et al. Hospital-Level evaluation of the effect of a national quality improvement programme: time-series analysis of registry data. BMJ Qual Saf 2020;29:623-35.

5 Aggarwal G, Peden CJ, Mohammed MA, et al. Evaluation of the Collaborative use of an evidence-based care bundle in emergency laparotomy. JAMA Surg 2019;154:e190145.

6 Joynt KE, Harris Y, Orav EJ, et al. Quality of care and patient outcomes in critical access rural hospitals. JAMA 2011;306:45-52.

7 Livingston EH, Elliott AC, Hynan LS, et al. When policy meets statistics: the very real effect that questionable statistical analysis has on limiting health care access for bariatric surgery. Arch Surg 2007;142:979-87. 